\title{
Programas de Cumplimiento: Un modelo para armar
}

Marco Bustinza Siu

Abogado por la Universidad Católica de Santa María. Magíster en Derecho Penal por la Pontificia Universidad Católica del Perú.

SUMARIO:

I. Introducción.

II. ¿Por qué existen los programas de cumplimiento? Un análisis desde una perspectiva de políticas públicas.

III. Los programas del cumplimiento desde la óptica de la imputación objetiva del comportamiento típico.

IV. La necesidad de pena decae.

* El artículo fue recibido con fecha 25-05-18. 


\title{
RESUMEN:
}

La presente contribución tiene como finalidad señalar fundamentos de los Programas de cumplimiento, tanto en las políticas públicas como en el Derecho penal, y denunciar los aciertos y desaciertos de una política criminal que en sí es adecuada y aún es perfectible.

Palabras Claves: programas de cumplimiento, Teoría de juegos, política criminal, política pública, ley penal.

\begin{abstract}
:
The purpose of this contribution is to identify the foundations of Compliance Programs, both in public policy and in criminal law, and to denounce the successes and failures of a criminal policy that is in itself adequate and still perfectible.

Key Words: Compliance Programs, Theory of Games, Criminal policy, Public policy, Criminal law.
\end{abstract}

\section{INTRODUCCIÓN}

Los programas de prevención en lo que atañe a riesgos penales tiene en nuestro sistema jurídico un programa coherente a evitar ilícitos penales - afectan el correcto desenvolvimiento de la Administración Pública- donde el Estado peruano forma parte; por citar solo un argumento de congruencia con el Derecho Convencional se encuentra en conformidad con la Convención de Naciones Unidas contra la lucha de la corrupción que la Resolución Legislativa 28357 de fecha 14 de diciembre de 2005 reconoce como parte de nuestro derecho interno'. De tal manera que la producción legislativa se ha orientado desde el punto de vista de la teoría de la evitabilidad de resultados disvaliosos ${ }^{2}$ a prevenir el cohecho activo genérico, cohecho activo transnacional, cohecho activo específico, además de evitar dentro de la organización empresarial la comisión u omisión del delito de lavado de activos en sus diferentes modalidades. Los instrumentos jurídicos promulgados, aún parecen ser insuficientes y sobre todo atomizados. Me explico, por una parte, se legisla sobre la necesidad de un buen gobierno corporativo a través de la adopción de programas de prevención destinados a evitar ilícitos que puedan generar asimetrías en la libre competencia ${ }^{3}$, que en caso de un proceso penal podría presuponer la atenuación o exención de las consecuencias accesorias a imponer a una organización empresarial. En otro contexto, en apariencia aislado se legisló sobre la colaboración eficaz de las personas jurídicas sin contener mayores baremos o criterios de medición de la proporcionalidad de las consecuencias accesorias a imponer a una persona jurídica de manera general, coexiste con estos instrumentos jurídicos el Reglamento de la colaboración eficaz de las personas jurídicas, pero que desde una perspectiva cetrina ${ }^{4}$, sólo servirá como una guía para sancionar a empresas del sector construcción

1. Véase por todos, Resolución Legislativa $N^{\circ}$ 28357. Disponible en: <http://www.idehpucp.pucp.edu.pe/images/ documentos/anticorrupcion/normativa/resolucion legislativa 28357-que aprueba convencion onu contra corrupcion.pdf $>$.

2. Cfr. GIMBERNAT ORDEIG, Enrique. Teoría de la evitabilidad versus teoría del aumento del riesgo, Vol. LXVIII. Madrid: ADPCP, 2015, pp. 1 y ss. También disponible en: <https://www.boe.es/publicaciones/anuarios derecho/ abrir pdf.php?id=ANU-P-2015-10002100062 ANUARIO DE DERECHO PENAL Y CIENCIAS PENALES Teor\%EDa de la evitabilidad versus teor\%EDa del aumento del riesgo>.

3. Esto en correspondencia con el artículo 61 de la Constitución del Estado que prescribe lo siguiente: “El Estado facilita y vigila la libre competencia. Combate toda práctica que la limite y el abuso de posiciones dominantes o monopólicas. Ninguna ley ni concertación puede autorizar ni establecer monopolios (...)"; este es leit motiv de la regulación por parte del Estado de buenas prácticas corporativas como veremos más adelante.

4. Nótese que se hace referencia al adjetivo de lo pálido: insuficiente. 
que hayan cometido actos de corrupción o de lavado de activos asumiendo una presunción de culpabilidad de los agentes inmersos, lo cual es un eterno retorno a lo mismo ${ }^{5}$, una política criminal reactiva a la coyuntura.

En lo que sigue se profundizará en las razones regulatorias por parte del Estado de incentivar los modelos de prevención de riesgos penales desde la faz de las políticas públicas. Y desde luego, las intermitencias con la Dogmática penal, en particular con la asunción de deberes positivos -ámbitos de competencia o incumbencia - como presupuestos del análisis de la imputación objetiva del comportamiento típico, y la justificación de la innecesaridad de aplicar consecuencias accesorias - penas - a las organizaciones empresariales desde el punto de vista de las teorías expresivas de la pena, un discurso más adecuado que el entendimiento propio de la prevención general positiva como tal.

\section{II. ¿POR QUÉ EXISTEN LOS PROGRAMAS DE CUMPLIMIENTO'? UN ANÁLISIS DESDE UNA PERSPECTIVA DE POLÍTICAS PÚBLICAS}

Una de las teorías que explica el porqué de la existencia de programas de cumplimiento es la teoría de la decisión ${ }^{7}$, parte de la premisa que cualquier hombre es egoísta por naturaleza y decidirá en su amplia libertad a maximizar sus beneficios en detrimento de los de otros actores, por ello tiene fundamento la creación de programas de cumplimiento para evitar accio- nes criminales. Sin embargo, la eficacia de estos programas de cumplimiento per se es limitada, por los desincentivos o incentivos que se puedan aplicar a través del marco punitivo o implicancias futuras de consecuencias accesorias.

La principal crítica a la teoría de la decisión ha venido de la aplicación de esquemas cooperativos como la teoría de los juegos en donde el comportamiento de los destinatarios de las normas -al igual que las normas primarias o directivas de conducta en el Derecho penales lograr una interacción eficaz entre los actores en un determinado sector de la economía. Esto hace que, dentro del cálculo en un ámbito racional, las relaciones entre los actores se tornen más eficaces, de manera independiente a no adoptar un programa de cumplimiento. Empero, si se trata de aplicar la teoría de los juegos en políticas públicas, estas reglas de carácter prescriptivo - normas en sentido lato- cuando se trate de la participación de más agentes en juegos no simultáneos, puede parecer que esta herramienta propia de la teoría de los juegos sólo puede servir como una base empírica, mas no teórica.

La necesidad de incluir programas de cumplimiento por parte del Estado, se encuentra en lograr los objetivos de la denominada: "Constitución Económica" que está orientada a garantizar la libre competencia en condiciones paritarias para todos los actores en el ámbito empresarial. En la actualidad se hace patente la necesidad de un estudio interdisciplinario

5. NIETZSCHE, Friedrich. Also sprach Zarathustra. Berlín: Goldmann Verlag, 2010, que en buena cuenta contiene como una de sus ideas principales cuestiones éticas que la humanidad no ha logrado resolver y seguirán patentes en nuestro discurso. También son de sugerir las ediciones en castellano en Alianza Editorial con prólogo de Antonio Sánchez Pascual.

6. La adopción de la frase: “Programas de cumplimiento" proviene de la traducción de los anglicismos: “Compliance Programs", en la literatura de otras lenguas e inclusive en otros países de nuestro continente reciben denominaciones distintas pero que significan lo mismo. Así en la literatura francesa y portuguesa se usa la frase: "Programas de conformidad" y en la reciente Ley Argentina de responsabilidad de las personas jurídicas se usa la denominación: "Programas de Integridad".

7. Introducidas en el debate de las políticas públicas por Gary Becker y Georges Stigler. Para una mejor comprensión de los autores mencionados: ETTIENE, Julien. La conformation des gouvernes. En: Revue Français de science politique, Vol. 3. París: 2010, pp. 493-517. 
de los programas de cumplimiento que van desde la filosofía - cuestión de tomar las mejores decisiones en una determinada circunstancia - hasta la economía cuyo sentido o epistemología se basa en tomar decisiones racionales ${ }^{8}$.

Entonces el Estado como ente regulador en función a que las propias organizaciones empresariales se autorregulen y cumplan con las políticas públicas que priorice un Estado Constitucional de Derecho como u desarrollo de los de derechos sociales o de segunda generación. $Y$ desde la vista de la Dogmática penal ello comporta el cumplimiento de deberes positivos, a los cuales los estudios contemporáneos ponen mayor énfasis que la sola evitación de resultados disvaliosos, bien sea desde la perspectiva de los deberes de solidaridad, o el prototipo del ciudadano solidario ${ }^{9}$, o desde la perspectiva del ciudadano deliberativo ${ }^{10}$.

\section{LOS PROGRAMAS DEL CUMPLIMIENTO DESDE LA ÓPTICA DE LA IMPUTACIÓN OBJETIVA DEL COMPORTAMIENTO TÍPICO}

Es necesario señalar algunos presupuestos de los cuales parte la teoría de la imputación objetiva, uno de ellos es entender a la teoría de las normas desde una perspectiva binaria: a) Normas primarias o directivas de conducta.- Son aquellas normas que contienen deberes negativos - no matarás-y deberes positivos tales como el acudir a una persona en riesgo de su integridad, sea como fuere estas normas están destinadas a un número indeterminado de destinarios;

b) Normas secundarias o de sanción.- Una vez comprobada la responsabilidad subjetiva del presunto autor, corresponde punir, esto según las sanciones que establezca cada tipo penal de la parte especial.

A nivel pretípico se han desarrollado diversos institutos que desgravan la responsabilidad penal del autor. Así, por ejemplo, la teoría de los roles ubica a cada ciudadano en el contexto delictivo para desde un análisis ex ante verificar si cumplía o no con los deberes estatuidos en normas del ámbito de su competencia, el riesgo permitido, a la fecha sigue siendo un criterio polémico porque presupone principios de causalidad concurrentes de manera necesaria en el resultado, lo cual aún es objeto de críticas"1, siendo un criterio para saber cuándo se está ya en el ámbito de lo ilícito, es decir del riesgo jurídicamente desaprobado ${ }^{12}$. Otro de los principios que opera es el de la prohibición de regreso, que a su vez se basa en dos subprincipios que la conforman: a) La prohibición de analizar

8. Ibíd., p. 516.

9. PAWLIK, Michael. Das unrecht des Burgers: Grundlinien der Allgemeinen Verbrechenslehre, Mohr Siebeck. Freiburg: 2012. Algunos artículos del mismo autor se pueden encontrar en la revista digital Indret penal.

10. KINDHÄUSER, Urs. La lógica de la construcción del delito. Disponible en: <https://www.unifr.ch/ddp1/derechopenal/articulos/a 20090918 02.pdf $>$. Tesis que proviene de los trabajos de Klaus Günther, según esta perspectiva el ciudadano deliberativo es el que conviene en ceder ciertos espacios de sus ámbitos de competencia-libertad- en beneficio propio y de la comunidad. En contraposición a las posturas del ciudadano fiel a Derecho, que tiene deberes de solidaridad que sólo operan como un deber de carácter normativo. Así, por ejemplo, un deber positivo contenido en nuestro Código penal es el del artículo 127 que hace referencia al ilícito penal de omisión de auxilio a persona en peligro o aviso a la autoridad. La Dogmática penal contemporánea parece cada vez más decidida a crear este tipo de deberes positivos sin injerir en el ámbito de libertad del individuo, problema que en realidad trasunta por la internalización de del contenido normativo a los posibles destinatarios.

11. Sobre este debate es muy enriquecedora la lectura de: AA.VV. Causalidad, riesgo, e imputación. Buenos Aires: Hamurabi, 2010, traducción de Marcelo Sancinetti.

12. FRISCH, Wolfang. Disvalor de acción y comportamiento típico. Madrid: Marcial Pons, 2006. 
todas las concausas ad infinitum, b) La teoría de la injerencia o de la incumbencia - deberes positivos o negativos más intensos en el contexto de la acción típica- que aún sigue siendo objeto de diversos desarrollos teóricos, la suma de estos dos factores da como resultado la conducta neutral, estereotipada a Derecho, o a la adecuación social ${ }^{13}$. Finalmente, a nivel anterior a la tipicidad objetiva se encuentra la autopuesta en peligro o imputación a la víctima, que desgrava al accionar típico del agente por trasladarse el ámbito de competencia al del sujeto pasivo. A grandes rasgos estas son las posibilidades de cuáles los institutos teóricos de la imputación objetiva que han tenido mayor relevancia en nuestra jurisprudencia.

Desde que una organización empresarial decide adoptar un programa de cumplimiento, asume la injerencia, el ámbito de competencia, de evitar resultados disvaliosos. Se compromete de alguna u otra manera a evitar si quiera a nivel de comportamiento típico de evitar ilícitos penales como el cohecho activo genérico, cohecho activo transnacional ${ }^{14}$, cohecho activo específico, y lavado de activos. Esto es el cumplimiento del deber positivo de prevenir ex ante los riesgos jurídicamente desaprobados por este bagaje normativo. $Y$ además en correspondencia con las políticas públicas del Estado peruano, acorde al desarrollo de la libre competencia.

\section{LA NECESIDAD DE PENA DECAE}

Toda explicación que se pretenda hacer de la funcionalidad de la prohibición de regreso como fundamento de los programas de cumplimiento tiene que estar en función de las teorías de la pena. Si bien es cierto, la prevención general positiva, asoma como una explicación plausible, no justifica de modo categórico por qué el Estado tendría que imponer una pena determinada a una organización empresarial, sobre todo en un sistema de consecuencia accesorias que se ha inclinado por la responsabilidad administrativa o vicarial.

Desde la óptica de las teorías de la expresión, y por influencia de las herramientas hermenéuticas propias de la Filosofía Analítica, como un acto del habla, donde el conflicto impera. ¿Se puede estar de acuerdo con la imposición de una pena? Desde luego que no, el Estado tendrá que justificar los motivos por los cuales se impone una pena determinada, y en esto se trata de comprender que tanto el destinatario de la norma como el Estado actúan desde su propio ámbito de libertad, y las cuotas de libertad que los ciudadanos hemos cedido en favor de nuestra seguridad por el ius puniendi, preestablecido en el contrato social. De nuevo el problema de legitimidad de imposición de penas pasa por una internalización patente de la norma directiva de conducta, o norma primaria, y esto en el ámbito de las organizaciones empresariales es de más fácil comprensión dada la homogeneidad de entender los incentivos de contar con un programa de cumplimiento ${ }^{15}$, cuestión que no es tan evidente cuando el cumplimiento de normas tiene como destinatarios hipotéticos a una sociedad heterogénea ${ }^{16}$.

En los programas de cumplimiento se pueden atenuar las normas de sanción - consecuencias accesorias - en contra de la persona jurídica, o se puede dar la exención, siempre y cuando se demuestre que el programa de prevención de riesgos penales estuvo vigente al momento de la comisión u omisión del presunto ilícito penal cometido por la organización empresarial. Desde el plano teórico, esta posibilidad de punir decae, porque la organización empresarial ha

13. La teoría de la injerencia o de la incumbencia también tiene su sustrato en los fines de preventivos generales positivos de la pena. Véase por todos: AA.VV. y JAKOBS, Günther. La prohibición de regreso. Bogotá: Universidad del Externado de Colombia, 1998, pp. 76 y ss.

14. Esto por política criminal trata de aproximarse a los criterios de la FCPA norteamericana que es extraterritorial.

15. Por ello, la aparición en nuestro Código penal del error de comprensión culturalmente condicionado. 
adoptado un programa de evitación de resultados lesivos desde una perspectiva ex ante.

Uno de los principales atavíos de los programas de cumplimiento es que la entidad que certificaría la funcionalidad o no de las medidas preventivas de la empresa $X$ sería la Superintendencia de Banca, Seguros y AFP-SBS, debiendo ser una cuestión propia del Ministerio Público hacer notar los lineamientos imprescindibles que deberá contar todo programa de prevención de riesgos penales. Si los riesgos son de carácter estrictamente penal, no tiene sentido que quien se encargue de verificar la funcionalidad o no de riesgos penales sean entidades dedicadas a verificar riesgos financieros o tributarios, o laborales, pero no de índole penal, aquí se requiere un análisis de mayor profundidad. De manera que aún tenemos leyes que incentivan los programas de cumplimiento, pero aún no existe el Reglamento del Decreto Legislativo 1352; y la dación este Reglamento debiera contar con la participación activa del Ministerio Público, porque será finalmente esta misma Institución que ante la eventualidad de casos concretos tenga que evaluar si los programas de cumplimiento en la práctica estaban destinados a evitar riesgos penales o no.
Se señalaba en la Introducción la política criminal reactiva del Estado peruano, si se quería dotar de un instrumento útil, se debió incluir el instituto de la colaboración eficaz de las personas jurídicas, pero desde una perspectiva orgánica, que, aunado a los programas de cumplimiento, se doten a sí mismos de normas de sanción claras. Lo que regula el Decreto Legislativo 1352, es sólo lo referido a multas ante la eventual funcionalidad o no de un programa de prevención de riesgos penales, pero de ninguna manera la Ley 30737 y su Reglamento contienen las sanciones que se aplicarán a la organización empresarial, pudiendo haber establecido la penalidad de la multa sola o de manera copulativa por el duplo o el quíntuple del beneficio obtenido, o haber optado por criminalizar a la empresa responsable que cumpla con tener un programa de cumplimiento con el tercio inferior de la pena ${ }^{17}$. Ninguno de esto criterios queda expresado en ninguna de las Leyes sobre responsabilidad penal de personas jurídicas. Una cuestión importante a integrar en favor de la seguridad jurídica, y partiendo del presupuesto del principio de presunción de inocencia que le asiste a toda persona sea natural o jurídica, y no de culpabilidad como ocurre en nuestra azorada coyuntura.

16. Desde la faz de las teorías expresivas de la pena, no dejan de ser interesantes los planteamientos deontológicos de: PÉREZ BARBERÁ, Gabriel. Problemas y perspectivas de las teorías expresivas de la pena. Barcelona: Indret, 2014, pp. 35 y ss.: "Con esta fundamentación no se instrumentaliza al autor del delito. Él mismo toma parte activamente y en igualdad de condiciones en el procedimiento justificatorio. No debería haber dudas, entonces, acerca del carácter deontológico de esa justificación. Ambas contrapartes discursivas están de acuerdo en que el mal desaprobatorio de la pena, como posible consecuencia del hecho punible cometido, se deriva de los compromisos que el propio autor del delito ha asumido a partir de su hecho, o que corresponde atribuirle, así como de lo que él mismo, siempre en virtud de su hecho punible, ha habilitado. Ambos concluyen, también, en que el autor del delito no puede considerar injusto lo que él, en libre ejercicio de su autonomía, ha habilitado, pues ello sería materialmente incompatible con su habilitación. Por el mismo motivo, coinciden las dos contrapartes discursivas en que el autor del delito no puede considerar injusto que se concrete aquello a lo que él se ha comprometido (la pena): "Nuestra dignidad como seres racionales consiste precisamente en estar obligados sólo por reglas que aceptamos, reglas que (como Ulises con las sirenas) hemos elegido libremente para someternos a ellas". Disponible en: <http://www.indret.com/pdf/1081.pdf $>$.

17. Una cuestión interesante ocurre en la Ley de Responsabilidad penal de las personas jurídicas en la Argentina. Disponible en: <http://servicios.infoleg.gob.ar/infoleglnternet/anexos/295000-299999/296846/norma.htm>. En particular resulta de relevancia los artículos 7 y 8. 